\title{
Estrategias educativas para la formación de investigadores en Medicina Familiar en México
}

\author{
Educational Strategies for the Training of Researchers in Family Medicine in Mexico \\ Estratégias educativas para a formação de pesquisadores em Medicina de Família no México
}

Alberto González-Pedraza Avilés, ${ }^{*}$ Rocío Dávila-Mendoza, ${ }^{*}$ María C. Ortiz-Zaragoza, ${ }^{*}$ Francisco J. Gómez-Clavelina*

\section{Introducción}

Es indudable que en México existe una clara conciencia sobre la importancia de la investigación, la cual ya no está limitada a ciertos círculos universitarios, sino que se ha extendido a los órganos decisivos del poder, así como a la mayoría de las instituciones educativas, del sector salud, e incluso, a empresas productivas de vanguardia, en especial del área social.

La pregunta que se genera es ¿los esfuerzos por desarrollar investigación científica y tecnológica tienen aún sentido y podrán sacar al país del círculo vicioso de la dependencia? Es obvio que la respuesta radica en el fortalecimiento de la investigación, al buscar espacios que permitan construir un sistema de investigación científica y tecnológica más sólido y menos dependiente.

Es en este contexto que la formación de investigadores cobra una importancia decisiva y estratégica. Si investigar es en la actualidad un quehacer tan importante, formar para la investigación efectiva debe ser una política de alcance no solo académico sino también social. ${ }^{1}$ En este sentido, uno de los retos es la formación de investigadores, que permita producir proyectos relevantes, pertinentes, con calidad metodológica y apegada a los principios éticos.
Con este propósito se creó el "Diplomado de metodología en investigación en salud" en la Subdivisión de Medicina Familiar de la División Estudios de Posgrado (DEP), Facultad de Medicina, Universidad Nacional Autónoma de México (UNAM), como estrategia educativa para introducir a los profesionales de la salud en el campo de la investigación aplicada. Existen, sin duda, múltiples metodologías para la formación de investigadores, no obstante, debemos ser conscientes acerca de la necesidad de hacer de la investigación un proceso pedagógico. ${ }^{2}$

La mediación pedagógica como estrategia alternativa se mueve dentro de ciertas coordenadas que hacen posible que el modelo temático de formación avance en la dirección y profundización del modelo pedagógico. Las coordenadas más pertinentes son las siguientes:

1. Todo lo que se haga en el proceso de formación de investigadores debe tener sentido para el investigador

2. Es precisamente el realizar investigación, la forma idónea para que se aprenda a desarrollar y perfeccionar las capacidades propias del investigador

3. La intuición debe constituirse como el punto de arranque y la fuerza propulsora del proceso de investigación

4. La investigación como proceso, y no tanto como logro de resultados, desarrolla y perfecciona la capacidad de investigar

El Plan de desarrollo de la Facultad de Medicina de la UNAM correspondiente al periodo 2008-2016, en su capítulo "Vinculación, Innovación y Desarrollo”, suscribe el programa de vinculación con

Este artículo debe citarse: González-Pedraza Avilés A, Dávila-Mendoza R, OrtizZaragoza MC, Gómez-Clavelina FJ. Estrategias educativas para la formación de investigadores en Medicina Familiar en México. Aten Fam. 2015;22(2):33-34.
"Subdivisión de Medicina Familiar, División de Estudios de Posgrado, Facultad de Medicina, Universidad Nacional Autónoma de México (UNAM). 
la sociedad, cuyo objetivo general es "enlazar las acciones de la Facultad de Medicina con el Sistema de Salud y las necesidades de salud de la población, así como difundir el conocimiento". ${ }^{3}$ De ahí que nuestro objetivo sea desarrollar una estrategia educativa para favorecer la formación de investigadores capaces de generar conocimiento que contribuya a la mejora de los procesos de atención médica.

\section{Propuesta metodológica}

La propuesta incluye las siguientes estrategias:

- Reconocer en los profesionales de la salud aquellos con el perfil necesario para favorecer su iniciación en la metodología de la investigación

- Sensibilizar al trabajador de la salud respecto a la utilidad e importancia de la investigación, no solo como una herramienta básica en la generación del conocimiento, sino como un instrumento que le permita mejorar su formación personal y profesional

- Transmitir los conocimientos propios de la metodología científica

- Favorecer el avance de la investigación, estableciendo un sistema de asesorías desde su desarrollo y hasta su conclusión

- Generar en el alumno la inquietud para mantener una capacitación constante y permanente en el aprendizaje del tema

- Apoyar al nuevo investigador para lograr la difusión de sus resultados

\section{Desarrollo de los diplomados}

La capacitación se inició en enero de 2008; para finales de 2014 se han desarrollado 13 diplomados, cinco sobre metodología de la investigación, uno relacionado con gerontología y siete con cuidados paliativos, todos con aval de la Subdivisión de Educación Continua de la DEP, Facultad de Medicina, UNAM. Han participado 320 profesionistas del área de la salud, lo que incluye a médicos generales, especialistas en Medicina Familiar, psicólogos, odontólogos, licenciados en Enfermería; químicos, licenciados en Nutrición y biólogos. Se han registrado 65 protocolos ante las instancias correspondientes, con base en las siguientes líneas de investigación: clínica, servicios de salud, epidemiología e investigación educativa. Como productos, se han presentado 28 trabajos en eventos académicos, 22 nacionales y 6 internacionales. Finalmente, se han publicado 19 trabajos en revistas indexadas -13 nacionales y 6 internacionales-.

\section{Conclusiones}

Es importante establecer la vinculación entre el sector salud y el sector educativo a nivel superior para favorecer la investigación, con el modelo propuesto ha sido posible despertar y favorecer en los trabajadores de la salud, inquietud y motivación por desarrollarla. Parte de las estrategias aquí planteadas para la formación de investigadores se fundamentan en cualidades o características naturales del ser humano, como son sus potencialidades, creatividad, curiosidad y entusiasmo; el papel del asesor básicamente consistió en fomentarlas, saberlas canalizar y crear condiciones para su desarrollo. Nos hacemos participes de la postura del quehacer artesanal en la formación de investigadores, conscientes de que la construcción científica es un saber hacer. Reconocemos la importancia de los asesores, para hacer participar al nuevo investigador de la valiosa labor que significa la producción de nuevos conocimientos.

\section{Referencias}

1. Sánchez Dromundo RA. La conformación del oficio de investigador en el doctorado en Pedagogía de la unam. Seminario permanente de investigación y formación sobre Pierre Bourdieu. Revista Latinoamericana de Estudios Educativos. 2010;XL:69-93.

2. Sánchez Puentes R. La formación de investigadores como quehacer artesanal. Ominia. 1987;3(9):11-24.

3. Facultad de Medicina. Plan de Desarrollo 20082016. [Internet]. [citado $2012 \mathrm{Feb} 20$ ] Disponible en: www.facmed.unam.mx/plan_2k8_2k16/ planfm_2k8_2k16 